\title{
Abdominal fat depots associated with insulin resistance and metabolic syndrome risk factors in black African young adults
}

\author{
Emanuella De Lucia Rolfe ${ }^{1 *}$, Ken K. Ong ${ }^{1,2}$, Alison Sleigh ${ }^{3,4}$, David B. Dunger ${ }^{2}$ and Shane A. Norris 2,5
}

\begin{abstract}
Background: Individuals of black African ethnicity tend to have less visceral adipose tissue (VAT) but more subcutaneous-abdominal adipose tissue (SCAT) than white Caucasians. However, it is unclear whether such distribution of abdominal fat is beneficial for metabolic disease risk in black individuals. Here we compared the associations between these specific abdominal fat depots, insulin sensitivity and metabolic syndrome risk.

Methods: A cross-sectional analysis of 76 black South African young adults (36 men; 40 women) aged 18-19 years participating in the Birth to Twenty Cohort Study had VAT and SCAT measured by MRI. The metabolic syndrome traits (blood pressure, lipid profile, fasting glucose and insulin) were measured and the values were combined into a metabolic syndrome risk score. Fasting glucose and insulin were used to derive the HOMA-index of insulin resistance (HOMA-IR).

Results: Compared to men, women had greater VAT (mean: 16.6 vs. $12.5 \mathrm{~cm}^{2}$ ) and SCAT (median $164.0 \mathrm{vs.} 59.9 \mathrm{~cm}^{2}$ ). In men, SCAT $(r=0.50)$ was more strongly correlated to the metabolic syndrome score (MetS) than was VAT $(r=0.23)$, and was associated with both MetS $(P=0.001)$ and HOMA-IR $(P=0.001)$ after adjustment for VAT and total fat mass. In women, both abdominal fat compartments showed comparable positive correlations with MetS ( $r=0.26$ to 0.31 ), although these trends were weaker than in men.
\end{abstract}

Conclusions: In young black South African adults, SCAT appears to be more relevant than VAT to metabolic syndrome traits.

\section{Background}

Obesity is a significant public health issue world-wide. In many middle- and low-income countries, obesity co-exists with under-nutrition and such 'double burden' of disease risk presents a difficult challenge for health services [1]. In South Africa, the prevalence of overweight or obesity is high in adolescents (30\% of girls; $10 \%$ of boys) and in adults (69\% of women; $39 \%$ of men) [2, 3].

The risk of obesity-related metabolic diseases may rise with increasing abdominal adiposity, in particular visceral (intra-abdominal) adiposity (VAT) [4, 5]. Many studies have reported ethnic differences in the risks of obesity-related metabolic diseases [6-8], which might be partly explained by ethnic differences in the distribution of abdominal fat

\footnotetext{
* Correspondence: ed219@mrc-epid.cam.ac.uk

'Medical Research Council Epidemiology Unit, University of Cambridge School of Clinical Medicine, Institute of Metabolic Science, Cambridge Biomedical Campus, Box 285, Cambridge CB2 0QQ, UK

Full list of author information is available at the end of the article
}

[9-11]. There is good evidence that individuals of black African origin have less VAT but more abdominal subcutaneous fat (abdominal SCAT) for the same degree of total body fat than white individuals [10, 12-14]. Despite these differences, black individuals are more hyperinsulinaemic and may have higher risk of type 2 diabetes (T2D) than white individuals $[15,16]$. Therefore, abdominal SCAT may actively contribute to the metabolic disturbances in black individuals, in whom positive associations have been reported with fasting and 2-h insulin levels [12, 17]. Abdominal SCAT has higher lipolytic activity than peripheral SCAT (gluteal-femoral or appendicular SCAT) and therefore releases substantially more free fatty acids into the systemic circulation [18, 19]. High free fatty acids levels are thought to increase peripheral insulin resistance by reducing glucose uptake in skeletal muscle [20, 21].

Abdominal SCAT is not homogeneous, but can be separated into deep (D-SCAT) and superficial subcutaneous 
(S-SCAT) compartments, differentiated by location relative to the fascia superficialis [22]. In animal models, D-SCAT is metabolically more active than S-SCAT [14], and a tendency to accumulate D-SCAT rather than S-SCAT could potentially explain the high metabolic disease risk in black individuals despite lower amounts of VAT. In some studies, among Pima Indians [22], mixed ethnicity [9] or undefined ethnicity [23, 24], D-SCAT and VAT showed similar strengths of association to metabolic syndrome traits, such as insulin resistance. Comparison of the metabolic correlates between different abdominal fat compartments could help to understand their biological relevance. In this study, we therefore examined whether total body fat, VAT, abdominal SCAT or its sub-compartments are related to metabolic syndrome traits in black South African young adults. We hypothesised that SCAT as well as VAT may have adverse metabolic consequences in this population.

\section{Methods}

\section{Study population}

A computer generated random sample of 100 healthy black South African young adults (48 men; 52 women) aged 18-19 years old participating in the Birth to Twenty cohort study (Bt20), were recruited to this study when they attended their annual data collection visit at the Chris Hani-Baragwanath Hospital, Soweto. Bt20 is a largescale longitudinal study of child and adolescent health and development, which started in 1989 [25]. Exclusion criteria for the current assessment included pregnancy. Cross-sectional analyses were performed on the final sample of 76 individuals (36 men; 40 women) who had complete data on MRI and metabolic traits. Missing data were due to technical issues and participant refusals to undergo MRI scanning or venous sampling. No significant differences were observed between individuals in the original study and those included in this analysis with regard to anthropometry and body composition (data not shown). The Ethics Committee on Human Subjects at the University of the Witwatersrand approved the study. Written informed consent was obtained from all study participants.

\section{Anthropometric measures and blood pressure}

Anthropometry included: weight measured in light clothing and barefoot to the nearest $0.1 \mathrm{~kg}$ using a digital scale (Tanita model TBF-410; Arlinghton Heights; USA); height measured barefoot to the nearest $0.1 \mathrm{~cm}$ using a wall mounted stadiometer (Holtain, Crymych, UK); waist and hip circumferences measured with a non-stretchable fibreglass insertion tape at the level of the umbilicus and at the largest gluteal diameter, respectively; and skinfold thicknesses measured with a Harpenden caliper at the biceps, triceps, subcapsular, and suprailiac sites. Trained staff performed all measurements. BMI was calculated as Weight $/$ Height $^{2}$ in $\mathrm{kg} / \mathrm{m}^{2}$.

Arterial blood pressure (BP) was measured in triplicate at 5-min intervals with an automated blood pressure monitor (Omron upper arm automated blood pressure machine; the Netherlands) with the participant rested and seated for at least $5 \mathrm{~min}$. The first measurement was discarded and the second and third were averaged.

\section{Body composition \\ MRI}

A whole body $1.5 \mathrm{~T}$ GE MRI scanner (GE Healthcare, Piscataway, NJ, USA) was used to acquire 17 respiratorygated, $\mathrm{T}_{1}$-weighted, water-suppressed, turbo spin echo transaxial images centred on the $\mathrm{L} 4$ vertebral level. The slice thickness was $10 \mathrm{~mm}$ ( $2 \mathrm{~mm}$ gap between slices), with an in-plane resolution of $0.94 \times 0.94 \mathrm{~mm}$, and a field of view of $480 \times 480 \mathrm{~mm}$. Cross-sectional VAT and abdominal SCAT areas were calculated from a single slice located at the L4 vertebral body by a semi-automated method, using an intensity thresholded map (Analyze 7.0, BIR, Mayo Clinic, Rochester MN) with manual input to differentiate between the abdominal fat compartments (Additional file 1: Figure S1). In some cases where there was artificial reduction in signal intensity due to artefacts in the MRI image, the threshold map was corrected by using the autotrace facility within the Analyze software. The same trained operator derived all of the MRI parameters.

The proportion of total abdominal fat (VAT + SCAT) attributable to VAT was also calculated as: VAT $\%=\left(V^{2} T^{*} 100\right) /$ (VAT+ abdominal SCAT). Abdominal SCAT was segregated into D-SCAT and S-SCAT using the fascia superficialis as the landmark. However, as abdominal SCAT showed near co-linear relationships with both D-SCAT and SSCAT $(r=0.96-0.98)$ both in men and women, these subcompartments were not considered in further analyses.

\section{Dual Energy $X$ ray Absorptiometry (DEXA)}

Total body fat mass $(\mathrm{kg})$ was derived using DEXA fan-beam technology (Hologic Discovery-W,) (Hologic, Bedford, MA, USA, Hologic Discovery Software version 12.1). Before the DEXA procedure was performed, the scanner was calibrated according to standard protocol using a high-density polyethylene phantom.

\section{Biochemical parameters}

Venous blood samples were collected following an overnight fast. Plasma glucose was measured by an autoanalyzer using standard enzymatic methods (Randox Laboratories; South Africa) and insulin was measured by Immulite (Siemens Chemiluminescent Technology). Blood lipids (total cholesterol, high and low-density lipoprotein and triglycerides) were measured by standard enzymatic methods 
(Randox Laboratories; South Africa). All assays were performed in one central laboratory.

\section{Metabolic risk factor score and HOMA-IR}

The metabolic syndrome traits (systolic and diastolic BP, lipid profile, fasting glucose and insulin) were combined into a metabolic syndrome risk factor score (MetS), based on International Diabetes Federation (IDF) criteria [26], but excluding the waist circumference component as central adiposity was considered here as the exposure. The following continuously distributed variables were converted to separate standardized scores: mean BP ([systolic BP + diastolic $\mathrm{BP}] / 2$ ), fasting insulin, fasting glucose, inverted fasting HDL-cholesterol, and fasting triglycerides. Standardization of each factor was performed by subtracting the sample mean from the individual mean and then dividing by the sample SD. MetS was then calculated as the mean of the five separate standardized scores [27]. Homeostasis model assessment estimates of fasting insulin resistance (HOMA-IR) were calculated as the product of fasting glucose $(\mathrm{mmol} / \mathrm{L})$ and fasting insulin $(\mu \mathrm{U} / \mathrm{mL})$ divided by 22.5 .

\section{Statistical analyses}

Statistical analyses were performed using Stata (version 12.0 StataCorp, College Station, Texas, USA). Descriptive data are presented as mean $\pm \mathrm{SD}$, or median and interquartile range. To examine whether the associations between SCAT and HOMA-IR or MetS differed between sexes, the interaction term (sex $\mathrm{x}$ SCAT) was added to the regression models. There was significant sex interaction in the association between SCAT and HOMA-IR, therefore all subsequent analyses were performed in men and women separately. Variables with a skewed distribution were log-transformed. Pearson coefficients were used first to describe inter-correlation between the various body composition and abdominal fat parameters, and then to describe the associations between these parameters and MetS or HOMA-IR. Regression models were derived to study the independent contributions of VAT and SCAT to the metabolic syndrome traits. As DEXA total body fat mass showed near co-linear relationships with SCAT $(r=0.90-0.93)$ both in men and women, this covariate was not considered in the final models.

Co-linearity between variables in the same model was indicated by a variance inflation factor $(\mathrm{VIF})>5$. To test for possible non-linearity, we compared linear models to a further model that included the quadratic term $\mathrm{SCAT}^{\wedge} 2$.

\section{Results}

Characteristics of the study population are summarised in Table 1. The sample comprised of men and women with a BMI range of $15.5-35.1 \mathrm{~kg} / \mathrm{m}^{2}$ for men and $15.2-46.0 \mathrm{~kg} / \mathrm{m}^{2}$ for women. Women had substantially higher abdominal SCAT than men (median 164.0 vs. $59.9 \mathrm{~cm}^{2}$, Fig. 1) and also higher VAT (mean 16.6 vs. $12.5 \mathrm{~cm}^{2}$ ), and BMI (mean 23.6 vs. $21.1 \mathrm{~kg} / \mathrm{m}^{2}$ ), fasting insulin levels (median 11.6 vs. $6.5 \mu \mathrm{U} / \mathrm{mL}$ ) and HOMA-IR (median 2.5 vs 1.4), but lower systolic BP than men (114.6 vs $125.0 \mathrm{mmHg}$ ) and no difference in MetS.

\section{Inter-correlations between body composition and abdominal fat parameters (Table 2)}

Correlations between VAT and abdominal SCAT were moderately strong (men $r=0.72$; women $r=0.63$ ). Total body fat mass (DEXA) was strongly correlated with abdominal SCAT (men $r=0.90$; women $r=0.93$ ) and showed moderately strong correlations with VAT (men $r=0.68$; women $r=0.66$ ).

\section{Associations with metabolic syndrome parameters}

In men, abdominal SCAT was more strongly correlated to MetS $(r=0.50 ; p=0.002)$ and HOMA-IR $(r=0.66$; $p<0.0001)$ than were VAT $(r=0.23 ; p=0.01$ and $r=0.40$; $p=0.2$, respectively), BMI ( $r=0.45 ; p=0.005$ and $r=0.52$; $p=0.001)$ or total body fat mass $(r=0.37 ; p=0.03$ and $r=0.58 ; p=0.0002$ ) (Table 3 ). In multivariate models, in men abdominal SCAT was independently associated with MetS $(P=0.004)$ and HOMA-IR $(P<0.001)$ after adjustment for VAT (Table 4).

In women, abdominal SCAT $(r=0.28 ; p=0.07)$ and VAT $(r=0.26 ; p=0.12)$ showed similar positive non-significant trends with MetS (Table 3). Similar strength trends with MetS were also seen in women for BMI $(r=0.31 ; p=0.05)$ and total body fat mass $(r=0.30 ; p=0.06)$, however these correlations were weaker than those seen in men. Multivariate models in women were unable to distinguish independent associations between abdominal SCAT or VAT on MetS and HOMA-IR (Table 4).

Correlations between the different body fat parameters and individual metabolic traits are shown in the Additional file 2: Table S1 and Additional file 3: Table S2. In men, abdominal SCAT was more related to fasting insulin and fasting glucose than other anthropometric/body composition measures (Additional file 2: Table S1). In women, abdominal SCAT and simple anthropometry were associated with blood pressure (systolic and diastolic) only (Additional file 3: Table S2).

\section{Discussion}

We observed, in young black South African men, that abdominal SCAT was more strongly related to insulin resistance and a combined metabolic syndrome risk factor score than were other body fat parameters, including VAT; furthermore, the metabolic relationships with abdominal SCAT were independent of VAT. In women, SCAT and VAT showed similar strength associations with 
Table 1 Anthropometry, body fat distribution and metabolic risk factors in South African young adults

\begin{tabular}{|c|c|c|c|}
\hline & Men $(n=36)$ & Women $(n=40)$ & $P$-value \\
\hline \multicolumn{4}{|l|}{ Anthropometry } \\
\hline Weight (kg) & $62.4 \pm 10.9$ & $60.6 \pm 14.0$ & 0.5 \\
\hline Height $(\mathrm{cm})$ & $172.0 \pm 6.0$ & $160.0 \pm 5.0$ & $<0.0001$ \\
\hline $\mathrm{BMI}\left(\mathrm{kg} / \mathrm{m}^{2}\right)$ & $21.1 \pm 3.6$ & $23.6 \pm 5.5$ & 0.02 \\
\hline Waist circumference (cm) & $74.8 \pm 9.4$ & $79.8 \pm 11.6$ & 0.04 \\
\hline Hip circumference $(\mathrm{cm})$ & $91.4 \pm 12.0$ & $100.3 \pm 12.7$ & 0.002 \\
\hline \multicolumn{4}{|l|}{$\mathrm{MRI}^{a}$} \\
\hline $\operatorname{VAT}{ }^{b}\left(\mathrm{~cm}^{2}\right)$ & $12.5 \pm 9.0$ & $16.6 \pm 8.3$ & 0.04 \\
\hline $\operatorname{SCAT}^{\mathrm{C}}\left(\mathrm{cm}^{2}\right)$ & 59.9 (35.9: 84.6) & $164.0(117.0 ; 266.9)$ & 0.0001 \\
\hline VAT/(VAT + SCAT) (\%) & $15.0(10.0 ; 20.0)$ & $7.4(5.7 ; 11.5)$ & $<0.0001$ \\
\hline \multicolumn{4}{|l|}{$D X A^{d}$} \\
\hline Total fat (\%) & $12.7(10.8 ; 15.0)$ & $33.1(26.4 ; 36.5)$ & 0.0001 \\
\hline Total fat mass $(\mathrm{kg})$ & $7.0(6.2 ; 9.5)$ & $17.6(14.0 ; 25.0)$ & 0.0001 \\
\hline \multicolumn{4}{|l|}{ Metabolic variables } \\
\hline Total cholesterol (mmol/L) & $3.6(3.0 ; 4.0)$ & $3.6(3.2 ; 4.3)$ & 0.7 \\
\hline LDL (mmol/L) & $1.9(1.4 ; 2.4)$ & $2.0(1.4 ; 2.4)$ & 0.9 \\
\hline $\mathrm{HDL}(\mathrm{mmol} / \mathrm{L})$ & $1.3(1.1 ; 1.4)$ & $1.3(1.2 ; 1.5)$ & 0.2 \\
\hline Triglycerides (mmol/L) & $0.66(0.51 ; 0.77)$ & $0.63(0.54 ; 0.76)$ & 0.9 \\
\hline Fasting insulin $\mu \mathrm{lU} / \mathrm{mL}$ & $6.5(4.1 ; 10.4)$ & $11.6(7.4 ; 12.9)$ & 0.001 \\
\hline Fasting glucose (mmol/L) & $5.2(4.8 ; 5.5)$ & $5.0(4.7 ; 5.4)$ & 0.5 \\
\hline Systolic BP (mmHg) & $125.0 \pm 10.1$ & $114.6 \pm 11.0$ & $<0.0001$ \\
\hline Diastolic BP (mmHg) & $71.9 \pm 7.5$ & $70.5 \pm 7.9$ & 0.5 \\
\hline \multicolumn{4}{|l|}{ Metabolic traits } \\
\hline HOMA-IR & $1.4(0.9 ; 2.4)$ & $2.5(1.7 ; 3.2)$ & 0.002 \\
\hline Metabolic risk factor score & $-0.3(-1.6 ; 1.5)$ & $0.3(-1.7 ; 1.5)$ & 0.9 \\
\hline
\end{tabular}

Data are means $( \pm \mathrm{SD})$ or median (interquartile range)

*Sex differences by T-test or kruskal-wallis non parametric test

${ }^{a} \mathrm{MRI}$ magnetic resonance imaging

${ }^{\text {b}}$ VAT visceral adipose tissue

'SCAT subcutaneous adipose tissue

${ }^{\mathrm{d}}$ Dual Energy x-ray absorptiometry

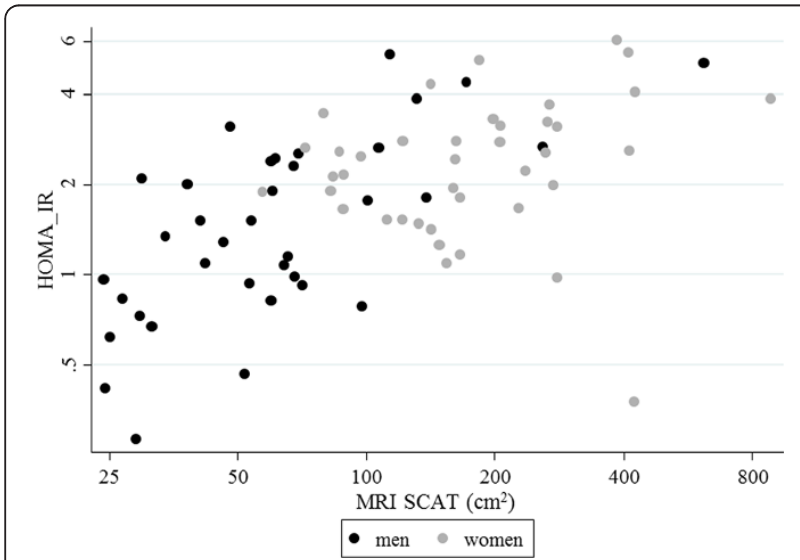

Fig. 1 Scatter plot of insulin resistance (HOMA-IR) against abdominal subcutaneous adipose tissue area (MRI SCAT) in black South African young men and women metabolic syndrome risk factors, which were also similar in strength to DEXA and anthropometry measures. Despite the lack of an apparent predominant effect of any one body fat parameter on metabolic syndrome traits within women, these women had on average nearly 3 -fold higher abdominal SCAT than men, which could explain their higher levels of insulin resistance. The lack of associations with metabolic traits in women could possibly be due to their limited range of SCAT, as only one woman had a SCAT value below the median value for men (see Fig. 1). Adverse consequences of abdominal SCAT could explain why black individuals are not protected against insulin resistance and T2D, despite relatively lower levels of VAT. However, as we did not study their white counterparts, it is still uncertain that this study demonstrates a different phenomenon in whites and in blacks. 
Table 2 Inter-correlations (Pearson's r) between anthropometry, body composition and abdominal fat parameters in men ( $n=36$ ) and women $(n=40)$

\begin{tabular}{|c|c|c|c|c|c|c|c|}
\hline & Weight & BMI & Waist & Hip & Total fat mass (DEXA) & $\operatorname{VAT}^{\mathrm{a}}(\mathrm{MRI})$ & $\mathrm{SCAT}^{\mathrm{b}}(\mathrm{MRI})$ \\
\hline \multicolumn{8}{|l|}{ Men } \\
\hline Weight & 1 & & & & & & \\
\hline BMI & 0.91 & 1 & & & & & \\
\hline Waist & 0.83 & 0.87 & 1 & & & & \\
\hline Hip & 0.83 & 0.62 & 0.62 & 1 & & & \\
\hline Total fat mass & 0.82 & 0.84 & 0.84 & 0.72 & 1 & & \\
\hline$V A T^{a}$ & 0.55 & 0.59 & 0.68 & 0.55 & 0.68 & 1 & \\
\hline$S C A T^{b}$ & 0.71 & 0.82 & 0.78 & 0.68 & 0.9 & 0.72 & 1 \\
\hline \multicolumn{8}{|l|}{ Women } \\
\hline Weight & 1 & & & & & & \\
\hline BMI & 0.96 & 1 & & & & & \\
\hline Waist & 0.81 & 0.82 & 1 & & & & \\
\hline Hip & 0.83 & 0.88 & 0.76 & 1 & & & \\
\hline Total fat mass & 0.87 & 0.89 & 0.67 & 0.81 & 1 & & \\
\hline$V A T^{a}$ & 0.62 & 0.63 & 0.5 & 0.6 & 0.66 & 1 & \\
\hline SCAT ${ }^{b}$ & 0.84 & 0.89 & 0.71 & 0.77 & 0.93 & 0.63 & 1 \\
\hline
\end{tabular}

$P<0.05$ for all correlations

aVAT visceral adipose tissue

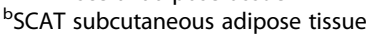

Previous studies have reported that abdominal SCAT shows stronger correlations with insulin resistance than does VAT: in middle-aged African American women [6], in non-diabetic overweight middle-aged African American women [28], and also in normal-weight African American young girls aged 7-10 years [29]. Conversely, Barnerji et al. reported that VAT but not SCAT was associated with insulin sensitivity in older African American adults with type 2 diabetes (32 men and 20 women, aged $48-54$ years) [30]. However, comparison to those studies may be limited as they were conducted in different ages and different settings. The relatively weaker associations that we observed in women might reflect a threshold effect of abdominal SCAT on metabolic risk.

Potential mechanisms have been suggested to explain the higher T2D risk in individuals of black African origin despite having less VAT [31]. Joffe et al. observed that black South Africans with T2D had diminished $\beta$-cell reserves leading to rapid exhaustion of insulin secretory capacity [32]. Reduced insulin secretion capacity in black Africans could arise due to genetic variants, for example in the gene encoding insulin promoter factor-1, a beta-cell specific transcription factor [13, 33-35], or consequent to exposure to undernutrition during infancy

Table 3 Pearson's correlation coefficients ( $P$-values) between body fat parameters and metabolic outcomes by sex

\begin{tabular}{|c|c|c|c|c|c|}
\hline & & \multicolumn{2}{|l|}{ Men $(n=36)$} & \multicolumn{2}{|c|}{ Women $(n=40)$} \\
\hline & & MetS & HOMA-IR & MetS & HOMA-IR \\
\hline \multirow[t]{4}{*}{ Anthropometry } & Weight & $0.32(0.056)$ & $0.43(0.009)$ & $0.27(0.09)$ & $0.18(0.24)$ \\
\hline & $\mathrm{BMI}$ & $0.45(0.005)$ & $0.52(0.001)$ & $0.31(0.049)$ & $0.22(0.20)$ \\
\hline & Waist & $0.26(0.12)$ & $0.50(0.002)$ & $0.17(0.28)$ & $0.15(0.34)$ \\
\hline & Hip & $0.26(0.12)$ & $0.34(0.03)$ & $0.26(0.10)$ & $0.19(0.23)$ \\
\hline DEXA & Total fat mass & $0.37(0.03)$ & $0.58(0.0002)$ & $0.30(0.059)$ & $0.15(0.35)$ \\
\hline \multirow[t]{2}{*}{ MRI } & $\mathrm{VAT}^{\mathrm{a}}$ & $0.23(0.20)$ & $0.40(0.01)$ & $0.26(0.12)$ & $0.12(0.46)$ \\
\hline & SCAT ${ }^{\mathrm{b}}$ & $0.50(0.002)$ & $0.66(<0.0001)$ & $0.28(0.07)$ & $0.18(0.27)$ \\
\hline
\end{tabular}

Correlations with $P$-values $<0.05$ are highlighted in bold

${ }^{a}$ VAT Visceral adipose tissue by MRI

${ }^{\text {b }}$ SCAT Subcutaneous adipose tissue by MRI 
Table 4 Independent contributions of VAT and SCAT parameters to the metabolic outcomes by sex

\begin{tabular}{|c|c|c|c|c|c|c|c|c|c|}
\hline & & \multicolumn{4}{|l|}{ Men $(n=36)$} & \multicolumn{4}{|l|}{ Women $(n=40)$} \\
\hline & & \multicolumn{2}{|l|}{ MetS } & \multicolumn{2}{|l|}{ HOMA-IR } & \multicolumn{2}{|l|}{ MetS } & \multicolumn{2}{|l|}{ HOMA-IR } \\
\hline & & $\beta(95 \% \mathrm{Cl})^{\mathrm{C}}$ & $P$ & $\overline{\beta(95 \% \mathrm{Cl})^{c}}$ & $P$ & $\overline{\beta(95 \% \mathrm{Cl})^{\mathrm{C}}}$ & $P$ & $\beta(95 \% \mathrm{Cl})^{c}$ & $P$ \\
\hline$\overline{\text { VAT }}$ & Model $1^{a}$ & $0.6(-0.03,0.2)$ & 0.1 & $0.03(0.01,0.06)$ & 0.01 & $0.6(-0.03,0.2)$ & 0.1 & $0.01(-0.01,0.03)$ & 0.5 \\
\hline SCAT & Model $1^{a}$ & $1.6(0.6,2.6)$ & 0.002 & $0.7(0.4,0.9)$ & $<0.001$ & $1.3(0.1,2.4)$ & 0.03 & $0.2(-0.1,0.5)$ & 0.3 \\
\hline VAT & Model $2^{b}$ & $0.001(-0.1,0.1)$ & 0.8 & $0.01(-0.02,0.04)$ & 0.7 & $0.05(-0.1,0.2)$ & 0.4 & $-0.001(-0.02,0.03)$ & 0.9 \\
\hline SCAT & Model $2^{b}$ & $2.2(0.8,3.6)$ & 0.004 & $0.8(0.4,1.2)$ & $<0.001$ & $1.2(-0.3,2.7)$ & 0.1 & $0.2(-0.2,0.5)$ & 0.4 \\
\hline
\end{tabular}

${ }^{a}$ Model 1 Univariate models

${ }^{\mathrm{b}}$ Model 2 Multivariate models including both VAT and SCAT

${ }^{c} \beta$ regression coefficient

or in utero [36, 37]. Our findings, suggest that preferential accumulation of abdominal SCAT in black young adults may have adverse consequences for insulin resistance and metabolic syndrome traits. However, it is yet unclear why abdominal SCAT might have greater adverse consequences in black Africans than in white Europeans. Early life exposures may play some role; Bto20 men had higher prevalence of early childhood stunting than women [38].

Limitations of our study include the modest sample size, which could have limited the power to identify associations with VAT, however this is compensated by the use of accurate and precise MRI imaging to quantify VAT and SCAT. Our analysis was cross-sectional, therefore we cannot exclude reverse-causality, i.e. possible effects of insulin and glucose metabolism on abdominal fat. Our population was young and the majority had healthy range BMI values; it is possible that associations between abdominal fat distribution and metabolic traits are stronger in older populations and in those with long-standing overweight or obesity. Although MRI assessment of SCAT and VAT has been validated [39] and it is generally accepted as a reference method to quantify these adipose depots [40], the fact that we quantified VAT and SCAT from only a single slice may be a limitation in our study as it may not fully capture the inter-individual variation in abdominal fat distribution [41]. However, we chose a standard MRI slice (at the L4 vertebrae) and our sensitivity analysis (which quantified VAT and SCAT at a lower single slice $36 \mathrm{~mm}$ lower, approximately at L5) revealed essentially similar findings (data not shown). We were unable to distinguish effects of deep and superficial SCAT, as these sub-compartments were almost completely co-linearly related to abdominal SCAT in our sample. We were also unable to differentiate between effects of abdominal SCAT and total fat mass, as these compartments were also co-linearly related. We did not adjust or stratify the analyses for other factors, such as physical activity, diet, early life factors and social factors. Future larger studies are needed to explore the potential contributions of those factors to metabolic syndrome traits in this population. We are not aware of other data on VAT and abdominal SCAT in similar aged healthy young adults; future studies are needed to confirm that the abdominal fat distributions observed here are representative of other black African populations.

\section{Conclusion}

In conclusion, in black South African young adults, SCAT may be equally, or even more, relevant than VAT to metabolic syndrome traits. The tendency for black individuals to accumulate SCAT rather than VAT is not necessarily beneficial to metabolic disease risks. Future studies should explore the early life determinants and current lifestyle correlates of abdominal fat distribution in black populations.

\section{Additional files}

Additional file 1: Figure S1. MRI image taken at the $L 4$ vertebral body, showing visceral adipose tissue (VAT) in green, superficial subcutaneous adipose tissue (S-SCAT) in blue, and deep subcutaneous adipose tissue. (D_SCAT) in pink. (TIFF $429 \mathrm{~kb}$ )

Additional file 2: Table S1. Pearson's correlation coefficients ( $P$-values) between body fat parameters and individual metabolic traits in men. (XLS $11 \mathrm{~kb}$ )

Additional file 3: Table S2. Pearson's correlation coefficients ( $P$-values) between body fat parameters and individual metabolic traits in women. (XLS $11 \mathrm{~kb})$

\section{Competing interests}

The authors declare that they have no competing interests.

\section{Authors' contributions}

EDLR: statistical analysis and manuscript preparation under the guidance of KKO and SAN. AS processed and analysed the MRI data and provided critical input on the data analysis. SAN, KKO and DBD conceived the idea of this study, were responsible for the overall design and in particular SAN managed and supervised data collection. All authors provided interpretation of the results, revised the different versions of the manuscript and approved the final version.

\section{Acknowledgements}

We are grateful to all the volunteers who took part in the study. We also thank Thabile Sibiya, Eliza Tsoeu, Modiehi Sedibe and Zanele Ngobese for assisting in data collection, Martin Manyike and Rhulani Mkansi for data management. The study was supported by the Medical Research Councils of South Africa and UK. Shane Norris is supported by the UK MRC/DFID Africa Research Leader Scheme. Alison Sleigh is funded by the NIHR via an award to the Cambridge NIHR/Wellcome Trust Clinical Research Facility. EDLR and $\mathrm{KO}$ are supported by the Medical Research Council (UK) [programme number MC_UU_12015/2]. 


\section{Author details}

${ }^{1}$ Medical Research Council Epidemiology Unit, University of Cambridge School of Clinical Medicine, Institute of Metabolic Science, Cambridge Biomedical Campus, Box 285, Cambridge CB2 0QQ, UK. ²Department of Paediatrics, University of Cambridge, Cambridge, UK. ${ }^{3}$ Wolfson Brain Imaging Centre, University of Cambridge School of Clinical Medicine, Cambridge Biomedical Campus, Cambridge, UK. ${ }^{4}$ National Institute for Health Research/ Wellcome Trust Cambridge Clinical Research Facility, Cambridge University Hospitals NHS Foundation Trust, Cambridge Biomedical Campus, Cambridge, UK. ${ }^{5} \mathrm{MRC}$ Wits Developmental Pathways for Health Research Unit, Department of Paediatrics, Faculty of Health Sciences, University of the Witwatersrand, Johannesburg, South Africa.

\section{Received: 29 June 2015 Accepted: 12 August 2015}

Published online: 05 October 2015

\section{References}

1. WHO. Obesity: preventing and managing the global epidemic: Report of a WHO Consultation. WHO Technical Report Series No. 894.2000. Geneva: World Health Organisation; 2000.

2. (SSISA). Healthy Active Kids, South Africa. Report card on the Physical Activity, Nutrition and Tobacco use for South African Children and Youth. Sport Science Institute of South Africa http://www.mrc.ac.za/chronic/ healthykids.pdf; 2007.

3. Ng M, Fleming T, Robinson M, Thomson B, Graetz N, Margono C, et al. Global, regional, and national prevalence of overweight and obesity in children and adults during 1980-2013: a systematic analysis for the Global Burden of Disease Study 2013. Lancet. 2014;384:766-81.

4. Després JP. Abdominal obesity: the most prevalent cause of the metabolic syndrome and related cardiometabolic risk. Eur Heart J Suppl. 2006;8(Suppl B):B4-12.

5. Preis SR, Massaro JM, Robins SJ, Hoffmann U, Vasan RS, Irlbeck T, et al. Abdominal subcutaneous and visceral adipose tissue and insulin resistance in the Framingham heart study. Obesity. 2010;18(11):2191-8.

6. Lovejoy JC, de la Bretonne JA, Klemperer M, Tulley R. Abdominal fat distribution and metabolic risk factors: effects of race. Metab Clin Exp. 1996:45(9):1119-24.

7. Duck MM, Hoffman RP. Impaired endothelial function in healthy AfricanAmerican adolescents compared with Caucasians. J Pediatr. 2007;150(4):400-6.

8. Weiss R, Dziura JD, Burgert TS, Taksali SE, Tamborlane WV, Caprio S. Ethnic differences in beta cell adaptation to insulin resistance in obese children and adolescents. Diabetologia. 2006:49(3):571-9.

9. Nazare JA, Smith JD, Borel AL, Haffner SM, Balkau B, Ross R, et al. Ethnic influences on the relations between abdominal subcutaneous and visceral adiposity, liver fat, and cardiometabolic risk profile: the International Study of Prediction of Intra-Abdominal Adiposity and Its Relationship With Cardiometabolic Risk/Intra-Abdominal Adiposity. Am J Clin Nutr. 2012:96(4):714-26.

10. Katzmarzyk PT, Bray GA, Greenway FL, Johnson WD, Newton Jr RL, Ravussin E, et al. Racial differences in abdominal depot-specific adiposity in white and African American adults. Am J Clin Nutr. 2010;91(1):7-15.

11. Lovejoy JC, Smith SR, Rood JC. Comparison of regional fat distribution and health risk factors in middle-aged white and African American women: The Healthy Transitions Study. Obes Res. 2001;9(1):10-6.

12. Goran MI, Nagy TR, Treuth MS, Trowbridge C, Dezenberg C, McGloin A, et al. Visceral fat in white and African American prepubertal children. Am J Clin Nutr. 1997;65(6):1703-8.

13. Gower BA, Fernandez JR, Beasley TM, Shriver MD, Goran MI. Using genetic admixture to explain racial differences in insulin-related phenotypes. Diabetes. 2003;52(4):1047-51.

14. Lee S, Kuk JL, Hannon TS, Arslanian SA. Race and gender differences in the relationships between anthropometrics and abdominal fat in youth. Obesity. 2008;16(5):1066-71.

15. Ryan AS, Nicklas BJ, Berman DM. Racial differences in insulin resistance and midthigh fat deposition in postmenopausal women. Obes Res. 2002;10(5):336-44.

16. Arslanian SA, Saad R, Lewy V, Danadian K, Janosky J. Hyperinsulinemia in african-american children: decreased insulin clearance and increased insulin secretion and its relationship to insulin sensitivity. Diabetes. 2002;51(10):3014-9.

17. Wagenknecht LE, Langefeld CD, Scherzinger AL, Norris JM, Haffner SM, Saad MF, et al. Insulin sensitivity, insulin secretion, and abdominal fat: the Insulin Resistance Atherosclerosis Study (IRAS) Family Study. Diabetes. 2003;52(10):2490-6.
18. Deschenes $D$, Couture $P$, Dupont $P$, Tchernof A. Subdivision of the subcutaneous adipose tissue compartment and lipid-lipoprotein levels in women. Obes Res. 2003;11(3):469-76.

19. Monzon JR, Basile R, Heneghan S, Udupi V, Green A. Lipolysis in adipocytes isolated from deep and superficial subcutaneous adipose tissue. Obes Res. 2002;10(4):266-9.

20. Kim JK, Wi JK, Youn JH. Plasma free fatty acids decrease insulin-stimulated skeletal muscle glucose uptake by suppressing glycolysis in conscious rats. Diabetes. 1996;45(4):446-53.

21. Abdul-Ghani MA, DeFronzo RA. Pathogenesis of insulin resistance in skeletal muscle. J Biomed Biotechnol. 2010;2010:476279.

22. Koska J, Stefan N, Votruba SB, Smith SR, Krakoff J, Bunt JC. Distribution of subcutaneous fat predicts insulin action in obesity in sex-specific manner. Obesity. 2008;16(9):2003-9.

23. Kelley DE, Thaete FL, Troost F, Huwe T, Goodpaster BH. Subdivisions of subcutaneous abdominal adipose tissue and insulin resistance. Am J Physiol Endocrinol Metab. 2000;278(5):E941-8.

24. Misra A, Garg A, Abate N, Peshock RM, Stray-Gundersen J, Grundy SM. Relationship of anterior and posterior subcutaneous abdominal fat to insulin sensitivity in nondiabetic men. Obes Res. 1997;5(2):93-9.

25. Yach D, Cameron N, Padayachee N, Wagstaff L, Richter L, Fonn S. Birth to ten: child health in South Africa in the 1990s. Rationale and methods of a birth cohort study. Paediatr Perinat Epidemiol. 1991;5(2):211-33.

26. Alberti KG, Eckel RH, Grundy SM, Zimmet PZ, Cleeman II, Donato KA, et al. Harmonizing the metabolic syndrome: a joint interim statement of the International Diabetes Federation Task Force on Epidemiology and Prevention; National Heart, Lung, and Blood Institute; American Heart Association; World Heart Federation; International Atherosclerosis Society; and International Association for the Study of Obesity. Circulation. 2009;120(16):1640-5.

27. Franks PW, Ekelund U, Brage S, Wong MY, Wareham NJ. Does the association of habitual physical activity with the metabolic syndrome differ by level of cardiorespiratory fitness? Diabetes Care. 2004;27(5):1187-93.

28. Tulloch-Reid MK, Hanson RL, Sebring NG, Reynolds JC, Premkumar A, Genovese DJ, et al. Both subcutaneous and visceral adipose tissue correlate highly with insulin resistance in african americans. Obes Res. 2004;12(8):1352-9.

29. Yanovski JA, Yanovski SZ, Filmer KM, Hubbard VS, Avila N, Lewis B, et al. Differences in body composition of black and white girls. Am J Clin Nutr. 1996;64(6):833-9.

30. Banerji MA, Lebowitz J, Chaiken RL, Gordon D, Kral JG, Lebovitz HE. Relationship of visceral adipose tissue and glucose disposal is independent of sex in black NIDDM subjects. Am J Physiol. 1997;273(2 Pt 1):E425-32.

31. Gaillard T, Schuster D, Osei K. Metabolic syndrome in Black people of the African diaspora: the paradox of current classification, definition and criteria. Ethn Dis. 2009;19(2 Suppl 2):S2. -1-7.

32. Joffe BI, Seftel HC. Diabetes mellitus in the black communities of southern Africa. J Intern Med. 1994;235(2):137-42.

33. Joffe BI, Wing JR, Zouvanis M, Pieterse A, Seftel HC. NIDDM in African-Americans and black South Africans: many similarities but some important differences. Diabetes Care. 1996;19(12):1451-2.

34. Karim MA, Wang X, Hale TC, Elbein SC. Insulin Promoter Factor 1 variation is associated with type 2 diabetes in African Americans. BMC Med Genet. 2005;6:37.

35. Higgins PB, Fernandez JR, Goran MI, Gower BA. Early ethnic difference in insulin-like growth factor-1 is associated with African genetic admixture. Pediatr Res. 2005;58(5):850-4.

36. Garofano A, Czernichow P, Breant B. Beta-cell mass and proliferation following late fetal and early postnatal malnutrition in the rat. Diabetologia. 1998;41(9):1114-20.

37. Hales CN, Barker DJ. Type 2 (non-insulin-dependent) diabetes mellitus: the thrifty phenotype hypothesis. Diabetologia. 1992;35(7):595-601.

38. Kimani-Murage EW, Kahn K, Pettifor JM, Tollman SM, Dunger DB, Gomez-Olive XF, et al. The prevalence of stunting, overweight and obesity, and metabolic disease risk in rural South African children. BMC Public Health. 2010;10:158.

39. Abate N, Burns D, Peshock RM, Garg A, Grundy SM. Estimation of adipose tissue mass by magnetic resonance imaging: validation against dissection in human cadavers. J Lipid Res. 1994;35(8):1490-6.

40. Klopfenstein BJ, Kim MS, Krisky CM, Szumowski J, Rooney WD, Purnell JQ. Comparison of $3 \mathrm{~T}$ MRI and $\mathrm{CT}$ for the measurement of visceral and subcutaneous adipose tissue in humans. Br J Radiol. 2012;85(1018):e826-30.

41. Greenfield JR, Samaras K, Chisholm DJ, Campbell LV. Regional intra-subject variability in abdominal adiposity limits usefulness of computed tomography. Obes Res. 2002;10(4):260-5. 